\title{
The profundity of mental Health during the COVID-19 pandemic
}

Singh A $\mathrm{AD}$

Avilasha Singh, MBBS Student, Kathmandu Medical College Teaching Hospital, Sinamangal, Kathmandu, Nepal.

\begin{abstract}
Mental health has always been stigmatised and overlooked. Since, anxiety and stress are natural responses while facing a threat of new diseases, this pandemic has shown us the importance of mental health. During this time there have been many triggers that have caused repercussions on people's mental health. Mental health crisis is on the rise. So, it is important to be able to tackle mental health problems as effectively as physical health problems, not only now but in the future as well, once and for all.
\end{abstract}

Key words: Anxiety; Coronavirus; Mental health.

\section{INTRODUCTION}

$\mathrm{n}$ the face of any threat or uncertainty, fear or stress is a natural response. ${ }^{1}$ So, not only physical health but mental health has also been affected significantly by the ongoing pandemic. Mental health has always been stigmatised and overlooked. The silently increasing mental health crisis amidst this pandemic has shed some light into its importance.

In Kaiser Family Foundation (KFF) Tracking Poll, conducted in mid-July, $53 \%$ of adults in the United States reported that their mental health had been negatively impacted due to stress over the coronavirus. This was significantly higher than the $32 \%$ reported in March, the first time this question was included in KFF polling. ${ }^{2}$

Access this article online

Website: www.jkmc.com.np

DOI: https://doi.org/10.3126/jkmc.v10i2.40072

HOW TO CITE

Singh A. The profundity of mental health during the COVID-19 pandemic. J Kathmandu Med Coll. 2021;10(2):104-5.

Address for correspondence

Avilasha Singh

MBBS Student

Kathmandu Medical College Teaching Hospital

Sinamangal, Kathmandu, Nepal.

E-mail: avilasha1996@gmail.com

Copyright @ 2021 Journal of Kathmandu Medical College (JKMC)

ISSN: 2019-1785 (Print), 2091-1793 (Online)

(i) (S) This work is licensed under a Creative Commons Attribution-Non Commercial 4.0 International License.

\section{CAUSES FOR MENTAL HEALTH CRISIS}

The world came to a halt as coronavirus disease 2019 (COVID-19) took over. Lockdown had been implemented in many countries and people's lives have been adversely affected. In Nepal, a countrywide lockdown came into effect on 24 March 2020. People have been locked inside their houses maintaining social isolation. During this time there have been many triggers that have caused repercussions on people's mental health. This pandemic has completely redefined people's lifestyles. While some people fear getting infected, others are anxious about the uncertainty and having no control over the situation. Fear and anxiety about a new disease can be overwhelming to some. Since the disease has been highly stigmatised, people who have contracted the disease are also under a state of constant worry and embarrassment.

From the anxiety of social isolation to the economic stress of losing their jobs, people have been facing numerous problems. New realities of working from home and online studying have added to this. ${ }^{1}$ People have also been experiencing a change in sleeping and eating patterns, loneliness, and brain fog. Depression and anxiety have become a cycle where one aids the other. Elderly, especially in isolation and those with cognitive decline/dementia, may become more anxious, stressed, agitated, and withdrawn. ${ }^{3}$ Moreover, there is a worsening of already existing chronic health conditions and mental illness.

To add to the problem the number of sexual assault cases has also been increasing during the lockdown. It has been difficult especially for the victims living with 
their abusers. This has led to the further downhill tumble of mental well-being.

\section{CURRENT STATE}

In Nepal since mid-March 2020, 1,350 people, including 319 children and 876 women have died by suicide as cited on $7^{\text {th }}$ October $2020 .{ }^{4}$ Suicide among adolescent girls has increased by almost 40 percent during the four months of lockdown compared to the previous year, with some increase among boys. ${ }^{4}$ Mental ill-being is a silent epidemic that has been spreading along with this global pandemic.

Things have been even worse for people already battling drug and alcohol addiction. According to a study done in the US, frequency of alcohol consumption has increased overall, 0.74 days ( $95 \% \mathrm{Cl}, 0.33-1.15$ days), an increase of $14 \%$ over the baseline of 5.48 days in $2019 .{ }^{5}$ Excessive alcohol use may lead to or worsen existing mental health problems, such as anxiety or depression. ${ }^{6}$

\section{STEPS TO BE TAKEN}

Hence, along with addressing the COVID-19 related physical health crisis, a national response that is a-whole-of-society approach for mental health is also required. This includes countering the pandemic-related adversities and maintaining uninterrupted services for severe mental health conditions even amidst the pandemic. $^{7}$
Besides the actions taken by the authorities, people themselves also play a key role. It is necessary to recognise that one's anxiety is completely normal. If COVID-19 is making one anxious then it would be good to minimise watching or reading the news. Seeking information only once or twice a day would be enough. Keeping regular routines and including activities that are good for our mental well-being like regular exercising, cleaning, singing, painting, or communicating ones apprehension with others would help a lot. ${ }^{3}$ In Shetland, Scotland, the doctors have been authorised to prescribe spending time with nature to their patients. ${ }^{8}$ More initiatives like these are required in psychiatric practice. Small acts of self-care must not be overlooked. In the end, there is always an option to seek medical help. Reaching out to health personnel for mental health-related problems must not be seen as a sign of weakness.

Learning more about the psychiatric and psychological aspects of any public health emergency from the perspectives of public and global mental health is what we need to focus on. ${ }^{9}$ Finally, the current momentum of interest must be brought to an advantage for catalysing mental health reforms for better future tackling of mental health crisis. ${ }^{7}$

\section{Conflict of interest: None}

Source(s) of support: None

\section{REFERENCES}

1. World Health Organization. Mental health and COVID-19 [Internet]. [cited 2020 Oct 7]. [Full Text]

2. Panchal N, Kamal R, Orgera K, Cox C, Garfield R, Hamel L, et al. The implications of COVID-19 for mental health and substance use [Internet]. Kaiser Family Foundation; 2020 Aug 21 [cited 2020 Oct 7]. [Full Text]

3. World Health Organization. Mental health and psychosocial considerations during the COVID-19 outbreak [Internet]. 2020 March 18 [cited 2020 Oct 7]. [Full Text]

4. United Nations Children's Emergency Fund. Working together to prevent suicide among children and young people in Nepal [Internet]. 2020 Sept 10 [cited 2020 Oct 7]. [Full Text]

5. Pollard MS, Tucker JS, Green HD Jr. Changes in adult alcohol use and consequences during the COVID-19 pandemic in the US. JAMA Netw Open. 2020 Sept 1;3(9):e2022942. [PubMed | Full Text | DOI]

6. Foulds JA, Adamson SJ, Boden JM, Williman JA, Mulder RT. Depression in patients / with alcohol use disorders: systematic review and meta-analysis of outcomes for independent and substance-induced disorders. J Affect Disord. 2015;185:47-59. [PubMed | Full Text | DOI]

7. United Nations. COVID-19 and the need for action on mental health [Internet]. 2020 May 13. [cited 2020 Oct 15]. [Full Text]

8. Dockrill P. Doctors in Scotland are literally prescribing nature to their patients. 2018 Oct 9 [cited 2020 Oct 15]. [Full Text]

9. Jakovljevic M, Bjedov S, Jaksic N, Jakovljevic I. COVID-19 Pandemia and Public and Global Mental Health from the Perspective of Global Health Security. Psychiatr Danub. 2020;32(1):6-14. [PubMed | Full Text | DOI] 